\title{
Adaptive and predictive control architecture of inland navigation networks in a global change context: application to the Cuinchy-Fontinettes reach *
}

\author{
E. Duviella ${ }^{*}$ L. Rajaoarisoa ${ }^{*}$ J. Blesa ${ }^{* *}$ K. Chuquet ${ }^{* * *}$ \\ * Univ Lille Nord de France, F-59000 Lille, France \\ MinesDouai, IA, F-59500 Douai, France \\ (e-mail: \{eric.duviella, lala.rajaoarisoa\}@mines-douai.fr). \\ ** Automatic Control Department, Universitat Politecnica de Catalunya, \\ Pla de Palau, 18, 08003 Barcelona, Spain \\ (email: joaquim.blesa@upc.ed) \\ *** VNF - Service de la navigation du Nord Pas-de-Calais \\ 37 rue du Plat, 59034 Lille Cedex, France (e-mail: \\ karine.chuquet@developpement-durable.gouv.fr)
}

\begin{abstract}
In this paper, an adaptive and predictive control architecture is proposed to improve the management of inland navigation networks in a global change context. This architecture aims at ensuring the seaworthiness conditions of inland navigation networks, and to improve the efficiency of the water resource management. It is based on supervision and prognosis modules which allow the estimation of the current state of the network, and the forecasting of the extreme event occurrence. According to these indicators and to the management constraints and objectives, control strategies of the inland navigation networks will be adapted to limit the impacts of the extreme events. To achieve this aim, three challenges are considered and discussed in this paper. The first one consists in proposing an accurate modeling approach of navigation reaches which are characterized by large scale, nonlinearities, time delays, unknown inputs and outputs, etc. The second one is to increase the knowledge about potentiality of extreme events, consequences of the climate change. The prediction of these events is rather complex due to their rarity, the spacio-temporal scale of the networks, etc. Finally, the third one is the pooling of the two first contributions, i.e. the model of the system and the knowledge about extreme events. Thus, the resilience of the system and the adaptation of the management strategies could be realized.
\end{abstract}

Keywords: Adaptive control, Predictive control, Supervision, Prognosis, Large scale system, Navigation system

\section{INTRODUCTION}

Inland navigation networks in the north of Europe cover more than $42,000 \mathrm{~km}$ of canals, rivers and canalized rivers. They are used to transport goods from sea to the continent's urban and industrial centers. They provide economic and environmental benefits (Mihic2011; Mallidis2012) by allowing an efficient, quieter, and safer transport of goods (Brand 2012). To promote this transport mode as alternative to land transport, infrastructures were built to accommodate large broad gauge boats with an increasing of the navigation schedules. It is the case in the North of France with the construction of the Seine-Nord canal. Moreover, benefiting of the progress on Information and Communication Technology (ICT), new sensors and actuators are implemented on the navigation reaches (Ten Broeke 2001; Fastenbauer 2007). These navigation reaches are often telecontrolled according to supervision architectures. The main control objective is to insure the seaworthiness requirements for the accommodation of the broad gauge boats. In particular, the

\footnotetext{
* This work is a contribution to the GEPET-Eau project which is granted in the framework of the GICC program of the French Ministry MEDDE, with the participation of the CGDD, the DGEC and the DGTIM.
}

water level of the navigation channels has to be close to a Normal Navigation Level (NNL). The control of the water level is strongly constrained by the increasing of the gauge of the boats, the navigation schedules but also by extreme events due to global change. It is now accepted that climate change can cause longer periods of drought and stronger and more frequent flood events.

The effect of global change has been largely studied since several years starting from meteorological models at the planetaryscale. Based on climatic scenarios, predictive models of the water resources which will be available in future horizon from 10 years to 100 years have been proposed in the literature. They are based on social, economic and environmental aspects (Davies 2011; Graveline 2012; Murray 2012). In order to consider smaller scales, downscaling methods are proposed in the literature. In (Boe 2009; Ducharne 2010), the hydrological cycle of the main French river basins in the global change context has been studied. In (Garcia 2011), J. M. Garcia-Ruiz et al. focalize the study on the Mediterranean basin. To highlight the issues for the navigation sector of the climate change, 
the PIANC ${ }^{1}$ organisation published in 2008 a report by considering various projected scenarios (EnviCom 2008). Future change projections suggest a global mean sea level rise of a few decimetres, a greater frequency and intensity of extreme weather events, a water temperature increase and a modification of the river morphology. The constraints linked to water supply and quality in inland navigation channels might be stronger and stronger. These conclusions are shared by other studies of the impact of climate change in U.K. (Iwac 2009; Arkell 2006) and China (Wang 2007). These studies are very instructive in relation to anticipating risks of climate change to the navigation. Some measures are also proposed for adapting the management of inland navigation networks in global change context. For waterway operation, it is recommended to implement new ICT on the networks, to improve the management of water flow with better forecasting methods of extreme events, to propose decision support systems which gather adaptive management strategies.

A structured framework is necessary to design new adaptive management strategies of inland navigation networks and to estimate its consequences on the water resource management. In (Duviella 2011), a supervision and hybrid control accommodation framework for reactive control of hydrographical networks composed of dams and interconnected rivers and channels, is proposed. It deals with a efficient water asset management via generic resource allocation. Although the proposed approach is based on supervision method and adaptive control strategies, it does not directly address the impacts due to climate change. Another interesting scheme to design adaptive management of water resources in a global change context is proposed in (Pouget 2012). A modeling tool called Water Change Modelling System (WCMS) is designed to integrate various models of the water cycle, such as hydrological, water management and water quality models. WCNS allows the creation of scenarios of extreme events according to a DPSIR framework (Driving Forces-Pressures-State-Impacts-Responses). However, this tool seems not being adapted to take into account the specificities of the management of inland navigation networks.

Thus, an adaptive and predictive control architecture is proposed in this paper to deal with the efficient management of these networks in a global change context. To achieve this aim, three challenges have to be considered. The first one consists in proposing an accurate modeling approach of navigation reaches. The second is to increase the knowledge about extreme events according to studies proposed in the literature. This knowledge is necessary to design realistic scenarios of extreme events. The third one is the pooling of the two first contributions. The proposed architecure is illustrated in the framework of a real system: the Cuinchy-Fontinettes reach (CFR) located in the North of France. The structure of the paper is the following: Section II is dedicated to the description of the Cuinchy-Fontinettes reach and to the management constraints of this system in a global change context. In Section III, the proposed architecture is presented. The modeling approach for inland navigation reach which is proposed in section IV. Section $\mathrm{V}$ is dedicated to the modeling step of extreme events, consequences of the climate change. In section VI, a simulation of a flood close to the CFR, and the functioning of the proposed architecture are shown. Finally, the summary and perspectives of this paper are given in section VII.

\footnotetext{
1 Permanent International Association of Navigation Congresses
}

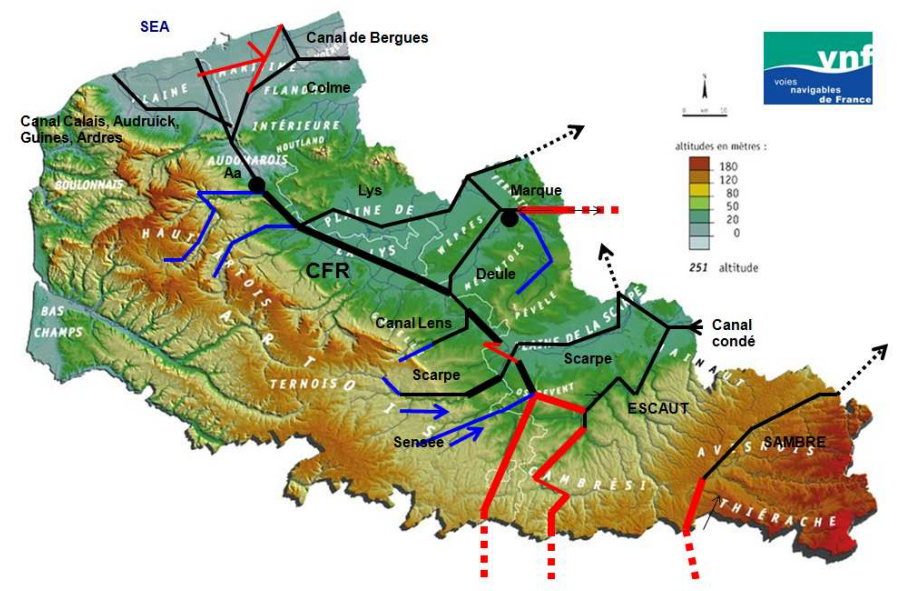

Fig. 1. Inland navigation network of the North of France.

\section{CUINCHY-FONTINETTES REACH}

\subsection{Presentation}

The inland navigation network in the North of France is a large scale system composed of interconnected rivers and channels (see Figure 1). This network is equipped with control gates and locks which are dedicated to the navigation task. Some channels are completely artificial and have a transverse position relative to the watershed. It is the case of the CFR. The CFR is located between the upstream lock of Cuinchy at the East of the town Bethune and the downstream lock of Fontinettes at the Southwest of the town Saint-Omer. The CFR is essential for navigation of broad gauge ships in the North of France. In effect, the Fontinettes lock allows to negociate a topological obstacle with a compensation of a waterfall of $13 \mathrm{~m}$ between the Lys and Aa watersheds. Also, due to the CFR localization at the cross of three of the principal catchment areas of the region, its management impacts directly the water resource availability for users, industrials etc.

The CFR is managed by VNF (Voies Navigables de France) whose role is to maintain its relative level at $N N L=4.26$ $m$ (Normal Navigation Level) for the navigation accommodation. To reach this aim, three points of the CFR must be controlled: the first is the Cuinchy lock and gate, the second is the Fontinettes lock and the third is the gate called "Porte de Garde". The lenght of the CFR is $42.3 \mathrm{~km}$ with a width equal to $52 \mathrm{~m}$ in average and no significant slope. The heigth of the lock at Fontinettes is $13 \mathrm{~m}$ whereas the lock at Cuinchy is only $2 \mathrm{~m}$. Considering the navigation flow, the water runs off from Cuinchy to Fontinettes. The control of Cuinchy and Fontinettes locks is principally constrained by the navigation demand. Each lock operation at Fontinettes leads to a consumption of water volume close to $25,000 \mathrm{~m}^{3}$. Moreover, a large number of intakes with anthropogenic origins (more than 320) supplies the CFR and often disturbes the control of water level.

\subsection{Management rules}

The management rules of inland navigation reach, especially for the CFR, consists in maintaining the NNL. this level is controlled with gates that supply water to the reach and compensate the effect of the locks that are opperated following the navigation requirements. The level of each reach is controlled 


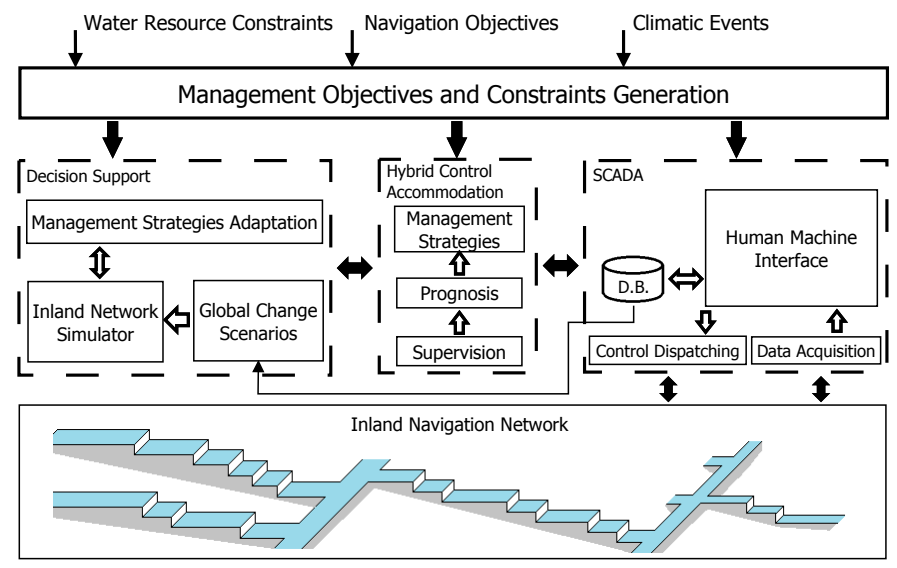

Fig. 2. Adaptive and predictive control architecture.

according to the level of upstream reach and several affluents when it is possible.

During drought periods, the priority given to the water use for navigation is the lowest compared to those for drinking water, for industry, for agriculture and for ecological aims. In effect, during these periods the water temperature can increase. The consequences are a modification of the ecosystem and a decrease of the oxygene in the water. It is necessary to circulate the water and thus operate the gates and locks. This leads to the decrease of the available volume of water. Under these strong constraints, it is necessary to accommodate the navigation. Thus, convoys of ships have to be planned.

During wet periods, the navigation channels are used to stock the maximum volume of water to avoid floods in the watersheds. For forecasted floods, the level of the channels are lowered by several centimeters, hours before their occurence. However, each navigation reach has a maximum limit. For the CFR this limit is $0.5 \mathrm{~m}$ up above the NNL. Beyond these maximum levels, a protocol submitted to prefectural decision is implemented to determine the area that will be impacted by the floods. In addition, even if this is not the case of the CFR, erosion phenomena might damage the navigation channels.

In a global change context, the drought and wet periods with occurence of floods will be increased. Thus, it is necessary to adapt the current management strategies of the inland navigation networks. To achieve these aims an adaptive and predictive control architecture is presented in the next section.

\section{ADAPTIVE AND PREDICTIVE CONTROL ARCHITECTURE}

An adaptive and predictive control architecture is proposed to improve the management of inland navigation networks against global change impacts (see Figure 2). This architecture is based on a SCADA (Supervisory Control And Data Acquisition) system which allows the tele-management of the network. Setpoints defined by the manager of the system or by the management strategies are sent to the actuators. The data measured on the network are saved in a data-base after a reconciliation step. This step is necessary to eliminate wrong data, and to detect faults on sensors or actuators. A Human Machine Interface (HMI) allows the supervision of the inland navigation network.
The control of the system is carried out according to the Management Objectives and Constraints Generation module (MOCG). This module regroups all the management protocoles. These ones take into account the navigation objectives, the constraints of the water resource uses and the climatic events.

The Hybrid Control Accommodation module (HCA) is composed of three blocks. The Supervision block consists in determining the current state of the system according to the measured data. The predictive characteristic of the architecture is included in the Prognosis block. It consists in forecasting the flood events and the drought periods, i.e. the future state of the system, according to predictive modeling approaches. Finally, the Management Strategies block defines the setpoints which have to be sent to the actuators of the system. Theses strategies can be adapted according to the Decision Support module (DS).

The DS module is designed to define adaptive management strategies of inland navigation networks, and to test the resilience of the inland navigation reaches. The resilience is defined as the capacity of the reach to resist to an extreme event. This module communicates with the MOCG and the HCA modules, and the SCADA via the HMI. The past events can take into account thanks to the data base. The DSM is based on three blocks. The Management Strategies Adaptation block (MSA) is used to design adaptive management strategies of inland navigation systems according to constraints and management objectives from the MOCG module and the current and forecasted states of the system. The Global Change Scenario block (GCS) aims at defining realistic scenarios of extreme events according to knowledge about the consequences of the global change, to past events and to predictive modeling approches. Finally, the Inland Navigation Simulator block (INS) is used to simulate the dynamics of inland navigation networks. This block is linked with the GCS and SM blocks in order to simulate extreme events and to test management strategies, respectively. A recursive step is proposed to test and to adapt the management strategies. Then, the results of the DS module, in particular the adaptive management strategies, can be applied on the real system via the HCA module. The design of the DS module requires the proposition of a model of the inland navigation reaches and a modeling step of extreme events.

\section{INLAND NAVIGATION REACH MODELING}

An inland navigation reach is an open-channel system characterized by large dimensions and nonlinear dynamics with varying delays. They have generally no significant slope and can be subjected to wave phenomena which are caused by operations of the locks (Blesa 2012; Clemmens 2012; Duviella 2013). According to the dimension of the locks, the amplitude of the wave can exceed several centimeters. The software SIC (Malaterre 2006) is used to model the dynamics of inland navigation reaches. This software can be easily coupled with Matlab/Simulink. The main advantage is that structure offers the possibility to develop models of the dynamics of locks or gates in Simulink, such as models of undershot gate and overshot gate (Euren 2007), or hybrid model of undershot/overshot gate (Le Porcher 2012).

The operation of a lock leads to a gain or a loss of a volume $V$ during a time $T$. This corresponds to a maximum discharge which goes in the reach or out the reach. It is modeled with a trapezoidal profile. For example, the operating of the Cuinchy 
lock corresponds to a volume of $3700 \mathrm{~m}^{3}$ during 6 minutes with a trapezoidal profile, and a maximum discharge equal to $10.8 \mathrm{~m}^{3} / \mathrm{s}$. The operating of the Fontinettes lock corresponds to a volume of $25000 \mathrm{~m}^{3}$ during 15 minutes with a trapezoidal profile, and a maximum discharge equal to $29 \mathrm{~m}^{3} / \mathrm{s}$.

\section{MODELING STEP OF EXTREME EVENTS}

\subsection{Characteristics of extreme events}

The modeling step of extreme events is divided in two parts. The first one consists in considering the drought periods, the second one the flood events. Even if both of these events impact the navigation task, they can not be modeled with the same approach.

While considering drought periods, scenarios due to global change consist in an elevation of the temperature and a decrease of available water resources. The time-scale of these events is generally large, i.e. from several days to several months. The space-scale is also large. To model drought events, it is possible to use the results of studies which are available in the literature, such as (Boe 2009; Ducharne 2010). These results have to be transposed to the North of France in order to define scenarios of drought. These scenarios could be sharpened by considering past drought events. In effect, a data base of more than 10 years is available.

The flood events are generally more localized and on smaller time-scales. The modeling of these events requires a good knowledge of the watershed dynamics and flood forecasting techniques. This knowledge is based on experience gathered from past floods occurred on several rivers (Pitt 2007), or historical studies (Sheffer 2008). In addition, several forecasting flood methods have been proposed in the literature. Some of them are based on rainfall/runoff models which involve a precise knowledge of the physico-geometric characteristics of the catchment areas (Calvo 2009; Laurain 2010). Others approaches based on stochastic models (Cloke 2009; Ramos 2012; Wetterhall 2013), artificial intelligence approaches (Talei 2010), or black-box model (Duviella 2012) can be used when the amount of data collected from the catchment area is sufficiently large and rich (over several years or decades period). The modeling of flood events is highlighted in the next subsection.

\subsection{Modeling step of flood events}

The modeling approach of flood events which are used in this paper was defined in (Duviella 2012). It is summarized herein. Its main advantage is that no prior knowledge about the characteristics of the watershed is necessary, but only a set of large enough historical data of the system. The rainfall/runoff relation is modeling according to a nonlinear black-box model. It is assumed that the rainfall and the water level in the river can be related by a model of the form:

$$
y(k)=\theta^{\top} \vartheta\left(\varphi_{H}(k)\right),
$$

where $\theta$ is a vector of parameters and $\varphi(k)$ is the regressor vector defined as

$$
\begin{aligned}
\varphi_{H}(k)=[y(k-H-1) & \ldots y\left(k-H-n_{a}\right) \\
u(k) & \left.u(k-1) \ldots u\left(k-H-n_{b}\right)\right]^{\top},
\end{aligned}
$$

where $y$ is the water level at one point of the river, $u$ is the rainfall, $n_{a}$ and $n_{b}$ are the orders of the model. The integer $H$ is the predictive horizon. $\vartheta$ is a nonlinear map from the space of the regressors $\mathbb{R}^{d}, d=n_{a}+n_{b}+H+1$, to $\mathbb{R}^{M+1}$ defined by:

$$
\vartheta(\varphi)=\left[\begin{array}{lll}
1 & \left.k\left(c_{1}, \varphi\right) \ldots k\left(c_{M}, \varphi\right)\right]^{\top} .
\end{array}\right.
$$

Here, the functions $k\left(c_{i}, \cdot\right), i=1, \ldots, M$, refer to a gaussian RBF (Radial Basis Function) defined on $\mathbb{R}^{d}$ by:

$$
k\left(c_{i}, \varphi\right)=\exp \left(\frac{\left\|c_{i}-\varphi_{H}\right\|_{2}^{2}}{2 \sigma^{2}}\right)
$$

with $c_{i}, i=1, \ldots, M$, denoting the so-called centers of the $\mathrm{RBF}$ and $\sigma^{2}>0$ its width. The vector $\theta=\left[\begin{array}{llll}\theta_{0} & \theta_{1} & \ldots & \theta_{M}\end{array}\right]^{\top}$ is the parameter vector to be estimated.

The parameter vector $\theta$ is determined by minimizing the cost functional

$$
\mathcal{J}(\theta)=\sum_{k=1}^{N}\left(y(k)-\theta^{\top} \vartheta(\varphi(k))\right)^{2}+\gamma\|\theta\|_{1}
$$

where $\|\theta\|_{1}=\left|\theta_{0}\right|+\ldots+\left|\theta_{M}\right|$ is the $\ell_{1}$-norm of $\theta$, and $\gamma$ is a regularisation parameter. The optimization algorithm which leads to the determination of $\theta$ is given in (Duviella 2012). The objectif is to predict at time $k$ the level of water in the next $f$ hours. Thus, it is necessary to compute $\hat{y}(k+f \mid k)$ based on the past inputs and outputs and the forecasted inputs (rainfall) $u(k), u(k+1), \ldots, u(k+f)$, where $f$ is the prediction horizon.

In this paper, the prediction of rainfall over 24 hours is considered available. In other case, uncertainties in the proposed modeling approach have to be taken into account to consider the stochastic properties of climate events. Anyway, the recursive property of the proposed algorithm seems robust against uncertainties because the model parameters are updated in continuous way.

\section{ADAPTIVE AND PREDICTIVE CONTROL OF THE CUINCHY-FONTINETTES REACH}

To show the functioning of the proposed architecture, a flood event scenario is built by considering the CFR. The simulation consists of one week of navigation with crossing of ships from Cuinchy and from Fontinettes, and of the occurence of the flood on a river which can supply the CFR thanks to the gate called Porte de Garde. The CFR is modeled with SIC (see Figure 3). The Cuinchy gate is a spillway. The Porte de Garde gate is located at $28.7 \mathrm{~km}$ from the Cuinchy lock. It is an undershot/overshot gate with an operating range of $Q_{L}= \pm 7$ $\mathrm{m}^{3} / \mathrm{s}$. The dynamics of these actuators is modeled according to approaches which are proposed in the literature (see section 4) and implemented using Simulink. The dynamics of the Cuinchy and Fontinettes locks during operation is given in section 4 .

The flood is built according to real data of rainfall and measured level, of one typical period of the year; automn (see Figure 4). The measured level is depicted in blue continuous line, and the predicted level in magenta dashed line. Levels are forecasted on a future horizon of 24 hours according to the proposed nonlinear black-box model. The parameters are tuned as $n a=10, n b=10,=4,=0.05$ and $M=30$. The forgetting factor is tuned as $=0.999$.

The main objective is to accommodate navigation with a CFR level in the operating range NNL $\pm 0.3 \mathrm{~m}$. In normal situation, 


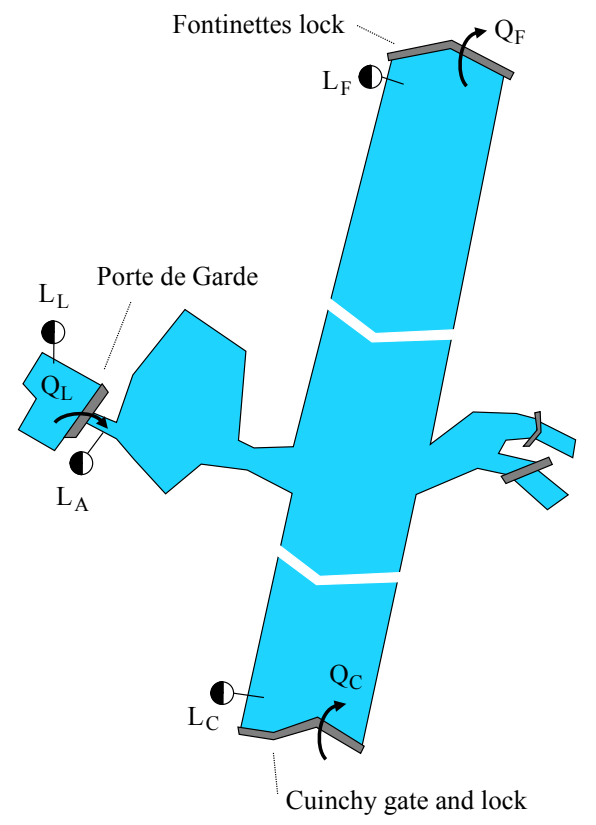

Fig. 3. Scheme of the Cuincy-Fontinettes navigation reach.
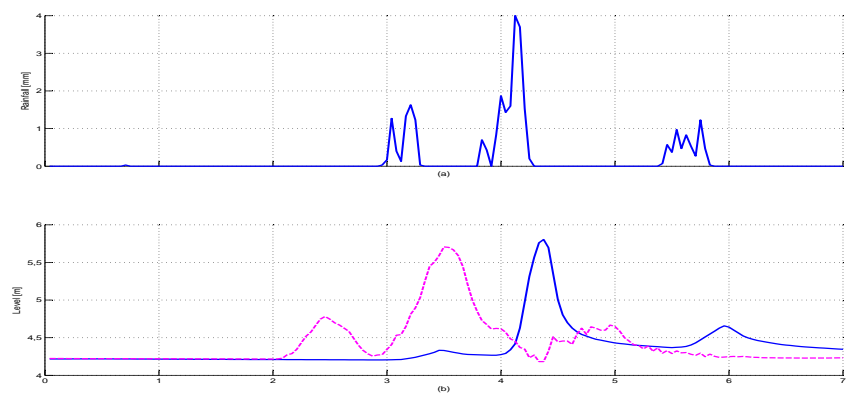

Fig. 4. (a) Rainfall and (b) the real (blue continuous) and pedicted (magenta dashed) water levels of the flood scenario.

to respect this condition, the discharge in Cuinchy $Q_{C}$ is equal to $2.4 \mathrm{~m}^{3} / \mathrm{s}$. The picks in Figure 5.b and 5.d correspond to the lock operations in Cuinchy and in Fontinettes, respectively. The flood occurs during the fourth day and it is forecasted 24 hours before (see Figure 5.a). As soon as the pick of flood is predicted, the discharge $Q_{C}$ is tune to 0 , excepted of the lock operations. During the occurrence of a flood, the maximum volume of water is stocked in the CFR with a maximum discharge $Q_{L}=7$ $\mathrm{m}^{3} / \mathrm{s}$ (see Figure 5.c). This maximum is reached during the occurence of the flood. Finally, the adaptive and predictive control of the CFR leads to limitation of the impact of the flood in the Lys river by a storage of maximum water volume in the CFR and allows the navigation. In fact, the levels of the CFR (see Figure 5.e) are kept in the navigation operating range.

\section{CONCLUSION}

The fundaments of an adaptative and predictive control architecture is proposed in this paper. This architecture is defined to improve the management of inland navigation networks in a global change context. It is based on a Hybrid Control Accommodation and Decision Support modules, and on also a SCADA system. An inland modeling method and a flood event forecasting approach are proposed to achieve the aims of these module. The proposed architecture is dedicated to the manage-
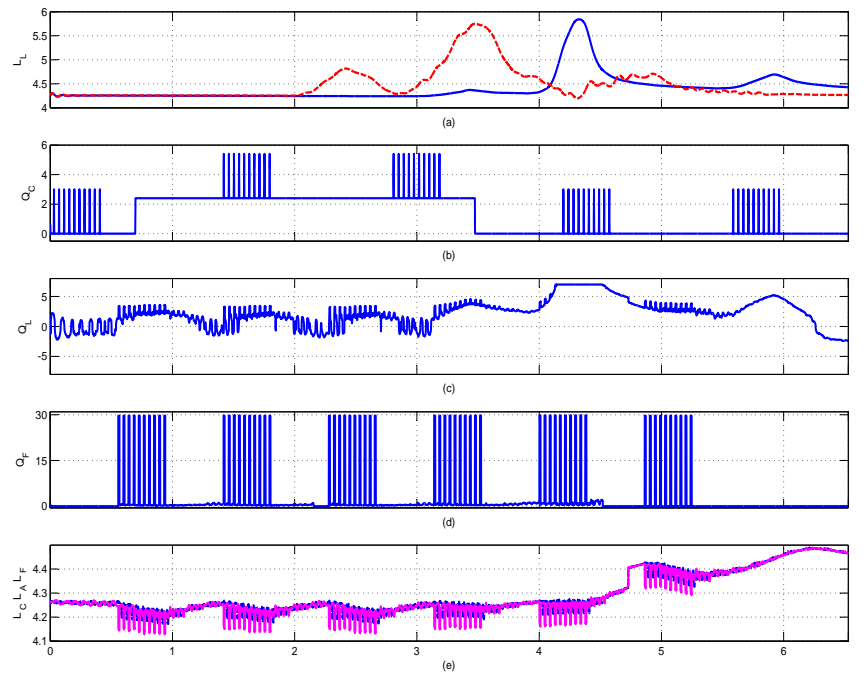

Fig. 5. (a) real (blue continuous) and predicted (red dashed) levels of Lys river, (b) Cuinchy discharge, (c) Lys discharge, (d) Fontinettes discharge and (e) Cuinchy (dashed line), Aire (dotted line) and Fontinettes (continuous line) levels of scenario 2 .

ment of a real inland navigation reach. Its efficiency is shown by simulation by considering a scenario of flood. In future works, it will be necessary to improve the modeling approaches of the inland navigation networks and of the extreme events. The SCADA architecture must also be developped according to existing tools.

\section{REFERENCES}

[Arkell 2006] Arkell, B.P. and G.J.C. Darch (2006), Impact of climate change on London's transport network, Proceedings of the ICE - Municipal Engineer, Volume 159, Issue 4, Pages 231237.

[Boe 2009] Boé, J., L. Terray, E. Martin and F. Habetsi (2009). Projected changes in components of the hydrological cycle in French river basins during the 21 st century. Water Resources Research, Volume 45.

[Blesa 2012] Blesa, J., E. Duviella, M. Sayed-Mouchaweh, V. Puig and K. Chuquet (2012), Automatic control to improve the seaworthiness conditions in inland navigation networks: application to a channel in the north of France, International conference on Maritime Transport, Barcelone, Spain.

[Brand 2012] Brand, C., M. Tran and J. Anable (2012). The UK transport carbon model: An integrated life cycle approach to explore low carbon futures, Energy Policy, Volume 41, Pages 107-124.

[Calvo 2009] Calvo, B. and F. Savi (2009). Real-time flood forecasting of the Tiber River in Rome. Natural Hazards, Volume 50, Issue 3, Pages 461-477.

[Clemmens 2012] Clemmens, A., Litrico, X., van Overloop, P., and Strand, R. (2012). Estimating Canal Pool Resonance with Auto Tune Variation. Journal of Irrigation and Drainage Engineering, Volume 138, Issue 1, Pages 915.

[Cloke 2009] Cloke, H. L. and F. Pappenberger (2009). Ensemble flood forecasting : A review. Journal of Hydrology, Volume 375, Pages 613-626.

[Davies 2011] Davies, E.G.R., S.P. Simonovic (2011). Global water resources modeling with an integrated model of 
the social-economic-environmental system. Advances in water resources, Volume 34, Pages 684-700.

[Ducharne 2010] Ducharne, A., F. Habets, C. Pagé, E. Sauquet, P. Viennot, M. Déqué, S. Gascoin, A. Hachour, E. Martin, L. Oudin, L. Terray and D. Thiéry (2010). Climate change impacts on Water Resources and Hydrological Extremes in Northern France. XVIII Conference on Computational Methods in Water Resources, June, Barcelona, Spain.

[Duviella 2011] Duviella, E., P. Chiron and P. Charbonnaud (2011). A reactive control strategy for networked hydrographical system management, Control Engineering Practice, Volume 19, Issue 8, Pages 851-861.

[Duviella 2012] Duviella, E. and L. Bako (2012). Predictive black-box modeling approaches for flow forecasting of the Liane river. Symposium on System Identification, Bruxelles, Belgium.

[Duviella 2013] Duviella, E., J. Blesa, L. Bako, Y. Bolea, M. Sayed-Mouchaweh, V. Puig and K. Chuquet (2013). Inland navigation channel model: Application to the Cuinchy-Fontinettes reach. International Conference on Networking, Sensing and Control - ICNSC, Paris-Evry University, France.

[EnviCom 2008] EnviCom - Task Group 3 (2008). Climate Change and Navigation - Waterborne transport, ports and waterways: A review of climate change drivers, impacts, responses and mitigation. EnviCom TG 3 - 2008 issue.

[Euren 2007] Euren, K. and E. Weyer (2007). System identification of open water channels with undershot and overshot gates. In Control Engineering Practice, Volume 15, Pages 813-824.

[Fastenbauer 2007] Fastenbauer, M., M. Sattler and G. Schilk (2007). River Information Services for commercial users in the Inland Waterway sector. In proceedings International Symposium on Logistics and Industrial Informatics. Wildau, Germany.

[Garcia 2011] Garcia-Ruiz, J. M., J.I. Lopez-Moreno and S. M. Vicente-Serrano (2011). Mediterranean water resources in a global change scenario. Earth-Science Reviews, Volume 105, Pages 121-139.

[Graveline 2012] Graveline, N., S. Loubier, G. Gleyses and J.D. Rinaudo (2012). Impact of farming on water resources: Assessing uncertainty with Monte Carlo simulations in global change context. Agricultural systems, Volume 108, Pages 29-41.

[Iwac 2009] IWAC Inland Waterways Advisory Council (2009). Climate change mitigation and adaptation. Implications for inland waterways in England and Wales.

[Laurain 2010] Laurain, V. (2010). Contributions à l'identification de modèles paramètriques non linéaires. Application à la modélisation de bassins versants ruraux. $\mathrm{PhD}$ thesis (available in english), University Henri Poincaré, Nancy.

[Le Porcher 2012] Le Pocher, O., E. Duviella, L. Bako and K. Chuquet (2012), Sensor fault detection of a real undershot/overshot gate based on physical and nonlinear blackbox models, Safeprocess, Mexico, Mexico.

[Litrico 2004] Litrico, X. and V. Fromion (2004). Simplified modeling of irrigation canals for controller design. Journal of Irrigation and Drainage Engineering, Volume 130, Num. 5, Pages 373-383.

[Malaterre 2006] P. O. Malaterre (2006), SIC 5.20, Simulation of irrigation canals, http://www.cemagref.net/sic/sicgb.htm.
[Mallidis2012] Mallidis, I., R. Dekker and D. Vlachos (2012). The impact of greening on supply chain design and cost: a case for a developing region, Journal of Transport Geography, Volume 22, Pages 118-128.

[Mihic2011] Mihic, S., M. Golusin and M. Mihajlovic (2011). Policy and promotion of sustainable inland waterway transport in Europe - Danube River, Renewable and Sustainable Energy Reviews, Volume 15, Issue 4, Pages 18011809.

[Murray 2012] Murray, S.J., P.N. Foster and I.C. Prentice (2012). Future global water resources with respect to climate change and water withdrawals as estimated by a dynamic global vegetation model, Journal of Hydrology, Volume 448-449, Pages 14-29.

[Pitt 2007] Pitt, M. (2007). Learning lessons from the 2007 floods: an independent review by Sir Michael Pitt. Interim report, London, UK.

[Pouget 2012] Pouget, L., I. Escaler, R. Guiu, S. Mc Ennis, P.A. Versini (2012). Global change adaptation in water resources management: The water change projet. Science of the total environment, Volume 400, Pages 186-193.

[Ramos 2012] Ramos, M. H., S. J. van Andel, and F. Pappenberger (2012). Do probabilistic forecasts lead to better decisions?. Hydrology and Earth System Sciences, Volume 9, Pages 13569-13607.

[Sheffer 2008] Sheffer, N.A., M. Rico, Y. Enzel, G. Benito and T. Grodek (2008). The Palaeofloodrecord of the Gardon River, France : A comparison with the extreme 2002 floodevent. Original Research Article Geomorphology, Volume 82, Issues 1-2, Pages 71-83.

[Talei 2010] Talei, A. L.H.C. Chua and C. Quek (2010). A novel application of a neuro-fuzzy computational technique in event-based rainfallrunoff modeling.Expert Systems with Applications, Volume 37, Issue 12, Pages 74567468.

[Ten Broeke 2001] Ten Broeke, I.A.A., C.P.M. Willems and C.C. Glansdorp (2001). A joint European effort to enhance safety and usability of the inland waterway network. In IEEE Intelligent Transportation Systems Conference Proceedings, Oakland (CA), USA.

[Wang 2007] Wang, S., S. Kang, L. Zhang, and F. Li (2007). Modelling hydrological response to different land-use and climate change scenarios in the Zamu River basin of northwest China. Hydrological Processes, Volume 22(14), Pages 2502-2510.

[Wetterhall 2013] Wetterhall, F., F. Pappenberger, H. L. Cloke, J. Thielen-del Pozo, S. Balabanova, J. Dahelka, A. Vogelbacher, P. Salamon, I. Carrasco, A. J. Cabrera-Tordera, M. Corzo-Toscano, M. Garcia-Padilla, R. J. Garcia-Sanchez, C. Ardilouze, S. Jurela, B. Terek, A. Csik, J., Casey, G. Stanknaviius, V. Ceres, E. Sprokkereef, J. Stam, E. Anghel, D. Vladikovic, C. Alionte Eklund, N. Hjerdt, H. Djerv, F. Holmberg, J. Nilsson, K. Nystrm, M. Sunik, M. Hazlinger and M. Holubecka (2013). Forecasters priorities for improving probabilistic flood forecasts. Hydrology and Earth System Sciences, Volume 10, Pages 2215-2242. 